\title{
DIPLOMACIA DIGITAL - O MODO NO DISCURSO DOS TWEETS: VICE-PRESIDENTE AMERICANO EM VISITA AO BRASIL
}

\section{DIGITAL DIPLOMACY - THE MODE IN TWEET DISCOURSE: AMERICAN VICE PRESIDENT VISITING BRAZIL}

\author{
Dina Maria Martins Ferreira* \\ Marco Antonio Vasconcelos ${ }^{\star \star}$
}

\section{RESUMO}

O objetivo deste trabalho é analisar a diplomacia digital norte-americana em relação ao Brasil durante a visita do vice-presidente americano ao Brasil em 2018, através do estudo do modo do discurso dos tweets. Para tanto, recorremos à Linguística Sistêmico-Funcional, centralmente às categorias relacionadas à função interpessoal da linguagem agregada à bibliografia sobre as relações internacionais Brasil-EUA. Os resultados mostram, através da marcante presença de elementos assertivos e passionalizadores, a construção de um perfil confiante, pragmático e patriótico em relação à defesa dos valores norte-americanos, com uma defesa substancial da família e da liberdade; não obstante a continuidade de certo monroísmo em relação à América Latina e ao Brasil.

Palavras-chave: tweets; diplomacia digital ${ }_{i}$ modo.

\section{ABSTRACT}

The aim of this paper is to analyze the North American public-digital diplomacy in relation to Brazil in 2018, through the study of Vice President Mike Pence's tweets during his stay in Brazil. For this purpose, we appealed to Systemic-Functional Linguistics, centrally to the categories related to the interpersonal function of language $\bar{i}_{\bar{i}}$ and the bibliography on BrazilUnited States international relations. The results show, through the remarkable presence of assertive and passionalizing elements, the construction of a confident, pragmatic and patriotic profile in relation to the defense of North American values, with a substantial defense of family and freedom; despite the continuity of a certain monroism in relation to Latin America and Brazil.

Keywords: tweets; digital diplomacy; mode.

* Universidade Estadual do Ceará, UEC, Fortaleza, CE, Brasi dinaferreira@terra.com.br Orcid: http://orcid.org/0000-0003-2585-497X

** Doutorando na Universidade Estadual do Ceará, UEC, Fortaleza, CE, Brasil. marco_clarinetista@ yahoo.com.br

Orcid: https://orcid.org/0000-0002-1656-9539 


\section{CONSIDERAÇÕES INICIAIS}

O twitter ${ }^{1}$ tornou-se uma imensa caixa de ressonância de trinados políticos. Os estadistas, percebendo isso, passaram também a gorjear entre 0 e 280 caracteres, buscando avolumar seu canto. Basta observar o falcão político Donald Trump, $45^{\circ}$ presidente dos Estados Unidos, que faz do twitter uma de suas principais ferramentas comunicacionais e diplomáticas ${ }^{2}$. De fato, o aparecimento da Internet e o recrudescimento das mídias sociais transformaram a esfera política, alterando e criando novas dinâmicas sociais (CASTELLS \& GERHARDT, 2000). Ou melhor, surgem atores sociais e movimentos políticos, por exemplo, digital influencers (influenciadores digitais) $^{3}$ e Movimento Brasil Livre (MBL), alterando a própria maneira de fazer diplomacia e guiar a política externa de um Estado-nação - a chamada diplomacia digital (HOMELS, 2015; PELLING, 2015).

Nos EUA, a chapa presidencial Donald Trump-Mike Pence, eleita para governar no período 2016-2020, fez das redes sociais e em especial do twitter um lugar privilegiado de comunicação governamental. Através de suas contas nessa rede, Trump e Pence dialogam com a população, rebatem críticas e acusações, divulgam e realizam ações no campo da política externa. Tendo por base os slogans American First (América Primeiro) e Make American Great Again (Fazer a América Grande de Novo), o governo republicano Trump-Pence adota, como discute Guida (2018), uma política externa revisionista e expansionista, subvertendo acordos ambientais internacionalmente pactuados, acirrando disputas econômicas com os chineses e

1. Twitter é uma rede social e servidor para microblogging (recurso que permite aos usuários enviar e receber atualizações pessoais de outros contatos com menos de 280 caracteres). Os textos são conhecidos como tweets, e podem ser enviados por meio do website (justaposição de web (rede) e site (sítio, lugar)) do serviço, por SMS (Short Message Service/Serviço de Pequenas Mensagens), por aplicativos específicos do Twitter para smartphones (telefone celular inteligente), tablets (tipo de computador portátil, formato de prancheta, para uso pessoal) e etc. Aliás, a palavra inglesa tweet significa pio de passarinhos, simbolizando os vários pios (pequenas mensagens) que se acumulam no timeline (linha do tempo) do Twitter. A partir deste conceito, foi desenvolvido também o logotipo da rede social - um pássaro azul -, que representa justamente a comunicação por meio de tweets, ou seja, de pios.

2. O termo diplomacia é registrado em português a partir de 1836 e advém do grego díplóma,matos, "objeto duplo, tablete de papel dobrado em dois", através do latim diploma, "papel dobrado, carta de recomendação, carta de licença ou privilégio" e do francês diplomatie (1790), "ciência dos diplomas" ou "relativo às relações políticas entre Estados ou referente aos diplomatas". Questão desenvolvida mais adiante sobre conceito de diplomacia e política externa.

3. Por se tratar de um estudo cujo locus é a mídia digital e consequentemente de uso do inglês-língua global, além de ser um artigo em português, nos preocupamos em manter os termos originais da linguagem digital, mas com tradução literal em português entre parênteses, a fim de atender a possível multiplicidade de tipos de leitores, que, muitas vezes, já naturalizou o sentido global e não dá mais conta dos sentidos originários. 
aumentando a pressão sobre países geopoliticamente importantes no que se refere à indústria do petróleo, tais como Venezuela e Irã. E no que se liga ao Brasil, o país passou a ser visto como elemento-chave para o restabelecimento da hegemonia estadunidense na América do Sul.

Em 2018, ano da eleição presidencial brasileira, um dos pontos altos das relações diplomáticas entre Brasil e EUA foi a visita do vice-presidente Mike Pence. O estadista veio discutir, com o presidente em exercício Michel Temer, questões importantes no que se refere à relação entre os dois países: situação das crianças separadas dos pais nos EUA, sobretaxação de importações ao aço e ao alumínio brasileiro e crise na Venezuela. Ao longo de sua estada no Brasil, Pence fez várias publicações no twitter, comentando a respeito de assuntos relacionados à sua visita, provocando nosso interesse em discutir tanto os direcionamentos da política externa dos EUA no que tange ao Brasil, quanto as novas formas de interação políticomidiáticas no contemporâneo - diplomacia digital norte-americana em relação ao Brasil ao longo de 2018.

É importante notar que utilizamos tanto os termos diplomacia quanto política externa. No entanto, diplomacia é um instrumento da política externa, para o estabelecimento e desenvolvimento dos contatos pacíficos entre os governos de diferentes Estados. E a política externa é definida em última análise pela Chefia de Governo de um país ou pela alta autoridade política de um sujeito de direito internacional. Enfim, a diplomacia pode ser entendida como uma ferramenta dedicada a planejar e executar a política externa. Além disso, figurativamente, ou de forma coloquial, chama-se diplomacia o uso de delicadeza ou os bons modos, ou, ainda, astúcia para tratar qualquer negócio, astúcia esta que mostra um discurso apaziguador e mutuamente interessado pelo mesmo fim, quando apenas o interesse hegemônico é preservado.

E para demonstrar este jogo diplomacia/política externa, recorremos à Linguística Sistêmico-Funcional, centralmente às categorias relacionadas à função interpessoal da linguagem e à bibliografia sobre as relações internacionais BrasilEUA.

\section{LINGUAGEM, SOCIEDADE E FUNÇÃO INTERPESSOAL}

A Linguística Sistêmico-Funcional é tributária de uma perspectiva funcional de linguagem. Nesse sentido, consoante Halliday (1989) e Halliday \& Matthiessen (2004), a função primária da linguagem é produzir significados, sendo a língua um conjunto de recursos através dos quais construímos o sentido da experiência 
humana, das relações sociais e dos textos. Segundo essa perspectiva, a prática semiótica, produtora de textos, gera uma gramática, isto é, um sistema de recursos construtores de significado no espaço de uma determinada língua. Nas interações sociais, esse sistema de recursos, tendo a oração como unidade fundamental, é instanciado em usos concretos, os quais, por sua vez, modificam a gramática que lhes deu ensejo.

Para investigar a relação entre ambiente social, organização funcional das línguas e significados produzidos, Halliday (1989) se utiliza da noção de contexto, ou seja, ambientes sociais nos quais os textos ocorrem. O referido conceito é de dupla dimensão: contexto de cultura e contexto de registro/situação. $\mathrm{O}$ contexto da cultura está ligado à história cultural dos participantes e ao tipo de práticas sociais nas quais eles estão envolvidos. Ou seja, ao encontro de Eggins (1994), refere-se à atividade social e à interpretação do uso da língua pelos seus usuários de maneira a fazer sentido em uma cultura, isto é, a um conjunto de sistemas de significação que se inter-relacionam. $\mathrm{O}$ contexto de registro/situação está ligado às atividades sociais realizadas dentro do ato comunicativo, levando em conta, portanto, a identidade dos participantes, as circunstâncias e a forma de construção do texto. Pode ser segmentado em três instâncias: campo, relações entre participantes e modo.

$\mathrm{Na}$ esteira de Halliday (1989), o campo estaria ligado à natureza da atividade social: os tipos de ações, seus participantes e circunstâncias. E as relações entre os participantes estariam ligadas à hierarquia, aos papéis e à distância social que eles estabelecem dentro do processo comunicativo. Já o modo estaria ligado ao papel da linguagem na interação: se o texto é construído em conjunto pelos interlocutores ou não; qual o canal de comunicação utilizado (áudio, oral, escrito, gráfico-visual); e o meio em que o texto é veiculado. Cada um desses elementos do contexto de situação, por seu turno, está relacionado a uma das chamadas metafunções da linguagem.

No processo de produção de sentido, a linguagem exerce três funções fundamentais no que tange às metafunções: constrói as experiências internas e externas, metafunção ideacional; estabelece relações com outras pessoas no meio social, metafunção interpessoal; e organiza as mensagens, metafunção textual. Todas essas metafunções acontecem juntas e a um só tempo, estando ligadas à criação de significados, sendo discriminadas apenas por razões teórico-analíticas. Do ponto de vista mais estritamente linguístico, a metafunção ideacional está mais ligada à transitividade; a interpessoal, ao modo oracional; e a textual, ao tema e ao rema. A transitividade está relacionada aos tipos de processos de participantes e de circunstâncias através dos quais uma dada experiência é significada; o modo 
oracional é correlacionado aos papéis de dar ou demandar informações ou bens e serviços e, na esteira disso, a seleção do modo, dos sujeitos e dos complementos verbais; e o tema o rema, elementos da função textual, estão coligados à construção e à hierarquização dos elementos dados e novos na estruturação da mensagem.

Nesse trabalho, nos concentramos na função interpessoal e no aspecto de troca informacional, em virtude da importância desses elementos no que se refere a questões diplomáticas. Sendo a função interpessoal a responsável por estabelecer os papéis e as relações que os interlocutores constroem no ato das trocas interativas, faz-se central na construção da interlocução entre os diferentes atores da política internacional.

A análise da oração como elemento de troca concentra-se no Modo. Este, na obra de Halliday \& Mathiessen (2004), pode ser visto, recorrendo a Bernardino (2015) em três níveis: Modo1, Modo2 e Modo3. Ao nível didático, o quadro a seguir organiza as categorias analíticas a serem utilizadas (sublinhadas) ${ }^{4}$ :

Quadro 1. Dinâmica/organização teórica

\begin{tabular}{|c|c|c|c|c|c|c|c|c|c|c|c|}
\hline \multicolumn{12}{|c|}{ CONTEXTO EM LINGUISTICA SISTÊMICO-FUNCIONAL } \\
\hline \multicolumn{11}{|c|}{$\begin{array}{l}\text { REGISTRO E SITUAÇÃOO } \\
\end{array}$} & CUL \\
\hline \multicolumn{11}{|c|}{ RELACC̃O ENTRE PARTICIPANTES } & \\
\hline \multicolumn{11}{|c|}{ METAFUNÇÕES } & \\
\hline \multicolumn{3}{|c|}{ CAMPO IDEACIONAL } & \multicolumn{6}{|c|}{ CAMPO INTERPESSOAL } & & $\begin{array}{l}\text { MPO } \\
\text { TUAL }\end{array}$ & \\
\hline \multicolumn{3}{|c|}{ TRANSITIVIDADE } & \multicolumn{6}{|c|}{ MODO ORACIONAL } & TEMA & REMA & \\
\hline \multirow[t]{3}{*}{$\begin{array}{c}\text { PR0- } \\
\text { CESSOS }\end{array}$} & \multirow[t]{3}{*}{$\begin{array}{c}\text { PARTI- } \\
\text { CI- } \\
\text { PANTES }\end{array}$} & \multirow[t]{3}{*}{$\begin{array}{l}\text { CIRCUNS- } \\
\text { TÂNCIAS }\end{array}$} & \multicolumn{3}{|c|}{ TROCA INFORMACIONAL } & \multicolumn{3}{|c|}{$\underline{M O D O}$} & $\begin{array}{l}\text { CONS } \\
\text { HIERA } \\
\text { ZAÇÃ } \\
\text { MENS }\end{array}$ & $\begin{array}{l}\text { UCÇ̃̃O } \\
\text { QUI- } \\
\text { DA } \\
\text { GEM }\end{array}$ & \\
\hline & & & \multicolumn{3}{|c|}{ SELEÇÃO } & & & & & & \\
\hline & & & MODO & SUJEITO & $\begin{array}{l}\text { COMPLE- } \\
\text { MENTOS } \\
\text { VERBAIS }\end{array}$ & $\underline{I}$ & $\underline{2}$ & $\underline{3}$ & & & \\
\hline
\end{tabular}

Sobre as três subcategorias presentes no Modo, temos: modo como tipo de função discursiva das interações, identificado como Modo1; modo como estrutura

4. As categorias em itálico demonstram a entrada das mesmas dentro da dinâmica teórica, com a finalidade de elucidar ao leitor o lócus teórico em seu todo. 
central da oração na qual estão os constituintes léxico-gramaticais dos significados interpessoais, Modo2; e modo como parte da estrutura interna do modo2, constituída por sujeito, finito e adjuntos modais, Modos.

Para dar curso a análise, se observam as funções discursivas das interações, isto é, elementos do Modo1, os quais estão segmentados em quatro processos: declarar, questionar, oferecer e comandar. Da escolha de uma dessas funções e de sua realização através de elementos gramaticais tipicamente escolhidos para codificá-las, a interrelação entre os interlocutores é estabelecida. Após, observamse os itens léxico-gramaticais, constituintes das estruturas das orações, isto é, investiga-se o Modo2. Este se segmenta em Modos e Resíduo, sendo aquele, Modo3, constituído de sujeito, de partícula verbal de finito e de adjuntos de modo, e este, o Resíduo, de predicador, de complementos e de adjuntos circunstanciais. Sobre o Modo2, é importante ressaltar, seguindo Halliday \& Mathiessen (2004), que o sujeito não deve ser pensando apenas como uma categoria gramatical, com função predominantemente sintática. Para além disso, os autores compreendem o sujeito como um importante elemento semântico da oração. Nesse sentido, pensá-lo, por exemplo, como o elemento em relação ao qual o ouvinte constrói afirmações, negações, questionamentos etc. faz-se uma tarefa fundamental. Ao encontro de Halliday \& Mathiessen (2004) e de Thompson (2002), é pertinente dizer que o sujeito fulcralmente expressa a entidade que o falante deseja tornar responsável pela validade da proposição. Já o finito, de acordo com Halliday \& Mathiessen (2004) e Thompson (2002), é o constituinte do Modos que nos possibilita localizar a proposição no tempo (presente, passado, futuro). Em razão disso, dá a ver a atitude do falante em relação à dimensão temporal na qual a proposição está inserida, orientando, pois, o ouvinte em direção à validade do que está sendo dito. Segundo Eggins (1994), o finito apresenta dois operadores verbais: os operadores de tempo e os operadores modais. Os primeiros ligados à ideia de tempo presente, passado ou futuro e os segundos às possibilidades ou obrigações envolvidas no que é dito: provável/improvável, desejável/indesejável etc. Não obstante, é importante dizer que o finito carrega também a ideia de polaridade, que está relacionada ao caráter positivo do auxiliar do (sim) ou do negativo don't (não) com que uma proposição é construída.

Em resumo gráfico, a retomada do modo oracional: 
Quadro 2. Modo oracional e suas subdivisões ${ }^{5}$

\begin{tabular}{|c|c|c|c|c|c|c|c|c|c|c|c|}
\hline \multicolumn{12}{|c|}{ MODO ORACIONAL } \\
\hline $\begin{array}{c}\text { TROCA } \\
\text { IN- }\end{array}$ & & & & \multicolumn{8}{|c|}{ MODO } \\
\hline & $\begin{array}{c}\text { MODOI } \\
\text { FUNCCÃO } \\
\text { DISCURSIVA }\end{array}$ & $\begin{array}{l}\text { MODO2 } \\
\text { ESTRUTURA } \\
\text { CENTRAL }\end{array}$ & \multicolumn{9}{|c|}{$\begin{array}{c}\text { MODO3 }= \\
\text { ESTRUTURA INTERNA DO MODO2 + CIRCUNSTÂNCIAS + } \\
\text { PARTICIPANTES }\end{array}$} \\
\hline & INTERAÇÕES & ORAÇÃOR & \multicolumn{4}{|c|}{$\begin{array}{l}\text { ADJUNTOS } \\
\text { MODAIS } \\
\text { (a) }\end{array}$} & \multicolumn{3}{|c|}{$\begin{array}{l}\text { ADJUNTOS . } \\
\text { CONJUNTIVOS/ } \\
\text { TEXTUAIS } \\
\text { (b) }\end{array}$} & \multicolumn{2}{|c|}{$\begin{array}{l}\text { ADJUNTOS } \\
\text { CIRCUNSTANCIAIS } \\
\text { (+RESÍDUO) } \\
\text { (c) }\end{array}$} \\
\hline & & & $\begin{array}{l}\mathrm{a} \\
1\end{array}$ & $\begin{array}{l}\mathrm{a} \\
2\end{array}$ & 3 & $\begin{array}{l}\mathrm{a} \\
4\end{array}$ & $\begin{array}{l}\mathrm{b} \\
\mathrm{l}\end{array}$ & $\begin{array}{l}\mathrm{b} \\
2\end{array}$ & $\begin{array}{l}\mathrm{b} \\
3\end{array}$ & $\begin{array}{l}\mathrm{c} \\
1\end{array}$ & $\begin{array}{l}\mathrm{c} \\
2\end{array}$ \\
\hline
\end{tabular}

Sobre a estrutura do Modo3, de acordo com Halliday \& Mathiessen (1994), o adjunto é o elemento que não tem o potencial de ser sujeito, não podendo ser a ele atribuída diretamente responsabilidade modal, mas que colabora para a construção das circunstâncias e dos participantes presentes na proposição. Ele é prototipicamente realizado por um grupo adverbial ou uma frase preposicional. Halliday \& Mathiessen (2004) os segmentam em três classes: (a) adjuntos modais, (b) adjuntos conjuntivos/textuais e (c) adjuntos circunstanciais.

Os (a) adjuntos modais são aqueles mais diretamente associados ao sistema de modo, imprimindo, ao dizer, significados de (a1) polaridade, (a2) de modalidade, (a3) de temporalidade e (a4) de modo. No significado de polaridade há dois níveis: positivo ou negativo. No contínuo entre eles, encontramos a modalidade. Esta, quando textualizada em termos de probabilidade e/ou usualidade (HALLIDAY \& MATHIESSEN, 2004) nomeiam modalização e, quando trabalhada em termos de obrigação ou inclinação, os autores chamam modulação. Ou seja, a variação entre os extremos da polaridade é chamada de modalidade, que se subdivide em dois tipos: modalização - ligada à ideia de probabilidade e/ou usualidade - e modulação - relacionada à ideia de obrigação ou inclinação. Ainda no espaço dos adjuntos modais, há os adjuntos de modo ${ }^{6}$. Eles expressam significados de obviedade (de fato,

5. Na explicação das categorias dentro do texto, para facilitar o leitor colocamos a numeração do quadro.

6. Adjunto Modal e adjuntos de modo não se confundem. Este é espécie daquele. Dentro do adjunto modal, há, além de do adjunto de modo, adjuntos ligados à ideia de polaridade, de modalidade e de temporalidade. 
obviamente, claramente), intensidade (somente, meramente, de fato, sempre) e grau (muito, escassamente, totalmente, completamente, quase).

Há os (b) adjuntos conjuntivos, de (b1) caráter textual, isto é, de (b2) construção estrutural. Sua função é estabelecer relações entre partes do texto, realizando (b3) uma função semântica de conexão.

Sobre os (c) adjuntos circunstanciais de tempo, estes podem ser subdivididos também em dois tipos: os adjuntos de (c1) tempo propriamente dito (ainda que, até agora, já, uma vez que) e os adjuntos de (c2) tipicidade (ocasionalmente, geralmente, regularmente, na maior parte das vezes. Os adjuntos circunstanciais adicionam conteúdo experiencial à oração, expressando alguma circunstância relacionada ao processo oracional. São, dessa forma, vinculados aos significados experienciais mais do que aos interpessoais, motivo pelo qual estão posicionados fora do Modo3, fazendo parte do Resíduo.

Em sinopse gráfica, temos os adjuntos modais, textuais e circunstanciais, partícipes do Modo3, de modos compartimentados:

Quadro 3. Adjuntos modais do Modo3

\begin{tabular}{|c|c|c|c|c|c|c|c|}
\hline \multicolumn{7}{|c|}{ ADJUNTOS MODAIS } \\
(a)
\end{tabular}

Quadro 4. Adjuntos textuais do Modo3

\begin{tabular}{|c|c|c|}
\hline \multicolumn{3}{|c|}{ ADJUNTOS TEXTUAIS } \\
(b) \\
\hline TEXTUAL & ESRUTURAL & CONEXÑO SEMÂNTICA \\
(b1) & (b3) & \\
\hline
\end{tabular}

Quadro 5. Adjuntos circunstanciais do Modo3

\begin{tabular}{|c|r|}
\hline \multicolumn{2}{|c|}{ ADJUNTOS CIRCUNSTANCIAIS (+ RESÍDUOS) } \\
(c) \\
\hline $\begin{array}{c}|c| \\
\text { TEMPO PROPRIAMENTE DITO } \\
(\mathrm{c} 1)\end{array}$ & TIPICIDADE \\
$(\mathrm{c} 2)$
\end{tabular}

Ao utilizarmos a linguagem, construímos, através do uso, um sistema de recursos que, posteriormente, influencia nossas próprias práticas linguísticas. 
Dessa perspectiva, centralmente tributária de Halliday (1989) e de Halliday \& Mathiessen (2004), a linguagem é um elemento tanto funcional quanto sistêmico, daí a ideia de uma linguística sistêmico-funcional. No campo do uso da linguagem nas interações sociais - função interpessoal -, as escolhas linguísticas estão diretamente relacionadas ao sistema de modo da língua. O referido sistema, na interação, oferece uma série de recursos capazes de construir um terreno de trocas e negociações entre papéis e identidades, construindo significados e efeitos de sentido que perfomatizam níveis de poder, relações de solidariedade e de intimidade e julgamentos e atitudes dos falantes um em relação ao interlocutor.

\section{OS ESTADOS UNIDOS DA AMÉRICA NA AMÉRICA LATINA}

A doutrina Monroe 7 , sintetizada pelo lema A América para os Americanos ${ }^{8}$, é a proposta que, de acordo com Gil (1989), efetivamente dá a tônica, do século XIX ao XXI, da política externa dos Estados Unidos em relação à América Latina e ao Brasil. Visando, de início, impedir a interferência dos Países Europeus sobre a América, a doutrina Monroe tornou-se uma forma de garantir o gerenciamento dos interesses socioeconômico dos estadunidenses sobre a América Latina. Através da combinação de soft $^{9}$ e bard power ${ }^{10}$, com o uso de medidas políticas, econômicas e mesmo militares para direcionar e impor certas ações e comportamentos, os EUA, de acordo com Guida (2018), no que se refere à América Latina, caracterizam-se por uma abordagem unilateral, centrando-se na efetivação dos próprios interesses. A relação EUA-Brasil, de acordo com Souto Maior (2015), é social e historicamente assimétrica, com evidente predominância dos interesses estadunidenses. Do alinhamento na Segunda Guerra Mundial, passando pela combate ao Comunismo até os acordos comercial no pós guerra-fria, o Brasil caracterizou-se, de maneira

7. Princípios enunciados pelo presidente norte-americano, James Monroe, em mensagem ao Congresso dos EUA, em 2 de dezembro de 1823. Surge como manifestação contra eventual intervenção das potências europeias nos destinos dos países do Novo Mundo, transformando-se rapidamente em princípio fundamental da política pan-americana da época. O Brasil aderiu integralmente aos seus enunciados.

8. No original: "America for the Americans". Ver Sexton (2011).

9. O soft power (poder suave) pode ser definido como "levar os outros a desejarem o que nos próprios desejamos (...) em determinar a agenda política para influenciar as preferências dos outros. O soft power também é mais do que persuasão ou a capacidade de convencer pessoas através de argumentação. É a capacidade de sedução e de atração. O soft power tem, em grande parte, origem nos nossos valores" (NYE, 2005).

10. Tomando Nye (2005), bard power (poder duro)designa a capacidade de um corpo político (geralmente, um Estado) de influenciar ou exercer poder sobre o comportamento de outro, mediante o emprego de recursos militares e econômicos. 
geral, como um defensor dos interesses estadunidenses, atuando como um dos parceiros centrais dos EUA no espaço da América Latina.

No final da primeira década do século XXI, com o governo Obama ${ }^{11}$, há, segundo Guida (2018), uma pequena modificação da forma de gestão da política externa dos EUA em relação ao continente americano. Em um mundo multipolar, no qual China e União Europeia disputam com os EUA espaço de influência econômica e política, adotam-se estratégias mais ligadas ao soft power, com a busca da implementação de uma politica de cooperação continental e da realização de uma abordagem multilateral. O conjunto de interreses estadunidenses - livre-comércio, segurança e promoção da democracia - continua o mesmo, mas a maneira de dar vazão a eles ganha um quê mais cooperativo.

Em 2017, com a eleição de Donald Trump nos EUA, há a modificação desse cenário. Através da adoção, segundo Kahl e Brands (2017), de uma política baseada no "nacionalismo econômico", " extrema segurança doméstica" e mesmo, consoante Posen (2018), da busca da implementação de uma "hegemonia antiliberal", a política externa dos EUA volta a se caracterizar pela abordagem unilateral e agressiva, com a preterição de instituições e de acordo multilateriais e com a adoção de uma abordagem em certo sentido imperialista. Através do documento National Stragery Security (US White House, 2017), delineam-se os elementos basilares da política externa norte-americana no governo Trump. Segundo Lefller (2017), há a adoção de uma visão hobbesiana do sistema internacional - vendo-o como uma ordem anárquica, caracterizada por poderes rivais conspiradores e agressivos e com atores não-estatais implacáveis e gananciosos - e de uma elevação da força imperialista, entendida como prosperidade econômica e poderio militar, ao posto de elemento central da política internacional. Em consequência disso, no que se refere à América Latina e ao Brasil, consoante Guida (2018), há a busca por revisão de acordos comerciais, de combate à influência da União Europeia e da China e de tentativa de isolamento de governos hostis como Cuba e Venezuela. Dessa forma, é possível dizer que se objetiva recuperar a perdida hegemonia e tornar América do Sul novamente algo dos (norte-)americanos.

Dentro dessa conjuntura, ainda segundo Guida (2018), Brasil e Venezuela são países-chave para o restabelecimento da pax americana, Brasil pela sua importância geopolítica, e Venezuela pela dimensão econômica. O Brasil é o maior país da América do Sul, tendo não só enorme extensão territórial, mas também enorme poder de influência sobre os vizinhos, sendo um espécie de epicentro dos acontecimentos da região. Já a Venezuela, governada por Nicolás Maduro, é um dos mais importantes

11. Presidente dos Estados Unidos no período de 20 de janeiro de 2009 a 20 de janeiro de 2017. 
produtores de petróleo do mundo, elemento central para o desenvolvimento da economia estadunidense. $\mathrm{O}$ ano de 2018 foi de grande importância para ambas as nações sul-americanas: o Brasil, em razão da ocorrência de eleições presidencial e parlamentar, em um cenário de crise econômica e crise política; e a Venezuela pela presença de uma catastrófica situação de hiperinflação, de restrição de liberdades civis e de êxodo em massa de seus habitantes para países vizinhos. E tal conjutura possivelmente motivou a visita do vice-presidente Mike Pence ao Brasil. Entre os dias 26 e 28 de junho de 2018, Mike Pence esteve no Brasil, objetivando discutir questões ligadas à situação das crianças brasileiras separadas dos pais nos EUA, a sobretaxação de importações ao aço e ao alumínio brasileiro e a crise na Venezuela ${ }^{12}$. Em seu twitter, ele fez vários comentários a respeito da sua estada e dos assuntos que veio tratar aqui.

\section{0 QUE E COMO GORJEAR}

Desde sua partida em direção ao Brasil até seu retorno aos EUA, o vicepresidente Mike Pence, em sua conta oficial ${ }^{13}$ no Twitter, postou 18 vezes sobre sua viagem ao Brasil ou sobre elementos correlacionados a ela. Nessas postagens, abordou, sobretudo, a respeito da crise na Venezuela e da importância do Brasil no que se refere à possível de intervenção para solucionar esta situação.

Para a seleção do corpus, adotamos dois critérios: ausência de imagens e menção direta ao Brasil. O primeiro critério se baseia na operacionalidade do trabalho, já que a análise de um texto predominantemente multimodal demandaria uma maior mobilização teórica; o segundo se baseia na estipulação do objetivo desse trabalho, ligada à investigação da dimensão diplomática no discurso de twitter. A partir desses critérios, selecionamos três tweets ${ }^{14}$

Sobre os procedimentos de análise do corpus, baseados em Halliday \& Mathiessen (2014), (1) realizamos a descrição dos elementos léxico-gramaticais ligados à função interpessoal; em seguida, (2) articulamos os dados ao contexto de registro; por fim, (3) discutimos as informações obtidas à luz do contexto de cultura ligado à situação da política (externa) estadunidense no que se refere ao Brasil.

12. Disponível em <https://g1.globo.com/politica/noticia/em-visita-ao-brasil-vice-de-trump-temencontro-com-temer-nesta-terca-feira.ghtml > . Acesso em: 09 dez.2018.

13. Disponível em: <https://twitter.com/search?l=\&q=from\%3AVP\%20since\%3A2018-06-26\%20 until\%3A2018-06-28\&src=typd\&lang=pt>. Acesso em: 09 dez. 2018.

14. Importante anotar que os três tweets não referendam uma generalização da diplomacia americana em relação ao Brasil e/ou América Latina, mas uma referência ao sentido discursivo veiculado no ciberespaço, como tópos de movimentação político-diplomática. 


\section{TRINADOS POLÍTICOS}

Michael Richard Pence nasceu em Columbus em 7 de junho de 1959 e é membro do partido republicano. Graduou-se em História e em Direito. É casado, desde 1985, com Karen Whitaker, com quem tem 3 filhos. Serviu na câmara dos deputados de 2001 a 2013 e foi, entre 2013 e 2017, governador de Indiana. Em junho de 2016, foi escolhido para ser o companheiro de chapa de Trump na corrida eleitoral para a presidência dos Estados Unidos. Ao final do ano, com a vitória de Trump, Mike Pence tornou-se vice-presidente, sendo considerado pela mídia estadunidense $^{15}$ uma figura central da gestão Trump, tendo bastante influência na condução do governo.

Mike Pence criou, em janeiro de 2017, no twitter, um perfil oficial como vicepresidente. Nele, posta textos quase que de maneira diária, escrevendo sobre os mais variados assuntos, desde tópicos ligados à economia e à política externa até sua vida familiar. Em 26 de junho de 2018, ele postou ${ }^{16}$ :

Vice President Mike Pence @VP - 26 de jun

Taking off to Brazil - on my 3rd trip to Latin America as Vice President. Look forward to working $\mathrm{w} /$ allies to put pressure on the Maduro regime to restore democracy for the Venezuelan people. @POTUS \& I are committed to ensuring the Western Hemisphere is a hemisphere of FREEDOM.

No primeiro período, "Decolando para o Brasil - na minha $3^{\mathrm{a}}$. viagem à América Latina como vice-presidente", ele contextualiza sua viagem para o Brasil. O Modo1 da oração é declarativo de polaridade positiva; no Modo2, há ausência de sujeito e de partícula verbal de finito; e em relação ao Modo3, sobre o predicador "decolando para", este se encontra no presente contínuo, dando ideia de continuidade à ação; sobre o complemento, temos o lexema "Brasil"; sobre o adjunto, "na minha $3^{\mathrm{a}}$. viagem à América Latina como vice-presidente", que tem caráter circunstancial, adicionando conteúdo experiencial à oração.

No segundo período "Espera-se trabalhar c/ os aliados para pressionar o regime de Maduro e (para) restaurar a democracia para o povo venezuelano", nos diz para observar o trabalho que estão realizando com os aliados para restaurar a democracia para o povo venezuelano. Em relação à estrutura oracional, no Modo1,

15. Disponível em: <https://www.politico.com/story/2016/12/mike-pence-power-play-trump-transition-232151>. Acesso em: 09 dez. 2018.

16. Tradução nossa, livre: "Decolando para o Brasil - na minha $3^{\mathrm{a}}$. viagem à América Latina como vice-presidente. Espera-se trabalhar c/ os aliados para pressionar o regime de Maduro e restaurar a democracia para o povo venezuelano. @POTUS e eu estamos compromissados em garantir que o Hemisfério Ocidental seja um hemisfério de LIBERDADE" 
temos a presença de um processo de comando; sobre o Modo2, há elipse de sujeito e de partícula verbal de finito; e sobre o Modos (e/ou Resíduo), há a presença do predicador "Espera-se"17, do complemento oracional "trabalhar" e dos adjuntos de circunstância: "com os aliados", "para pressionar" " e restaurar a democracia para o povo venezuelano", que indicam a companhia e a finalidade das ações que estão sendo realizadas. A polaridade da oração é positiva.

No terceiro e último período, "@POTUS e eu comprometemo-nos a garantir que o Hemisfério Ocidental seja um hemisfério de LIBERDADE", nos diz que está buscando, junto com Trump ${ }^{18}$, transformar o hemisfério ocidental em um hemisfério de liberdade. A respeito do Modo1, temos a presença de uma declaração de polaridade positiva; sobre o Modo2, há a presença do sujeito "@POTUS e eu", da partícula verbal de finito "estamos"; ; em relação ao Modo3, há presença do predicador "compromissados" e do adjunto circunstancial "em assegurar que o Hemisfério Ocidental seja um hemisfério de LIBERDADE".

Sobre esse tweet, no que se liga ao Modo1, chama a atenção a presença do modo declarativo e imperativo, com a presença de polaridade positiva. Esse tipo de uso, pela assertividade, pode acabar contribuindo para a construção de uma relação de confiança e de segurança ao que diz.

No que se refere ao Modo2, no período 1 e 2, chama a atenção a ausência de marcação de sujeito e tempo verbal finito ${ }^{19}$, o que enfatiza a ação que está sendo realizada, no caso a ação de "Decolando para " e de "(esperamos) trabalhar", recurso que pode salientar o trabalho realizado por Pence. Já no período 3, há presença de sujeito e de finito, quando @POTUS (twitter de Trump) e o próprio Pence são os sujeitos da oração, forma de uso da linguagem que pode colaborar para enfatizar a proatividade e o compromisso dos políticos em relação ao trabalho que está sendo realizado.

Sobre o Modo3, chama atenção a presença dos adjuntos circunstanciais: no período 1 , explica a viagem como "em minha $3^{\text {a }}$. viagem como vice-presidente"; no período 2 e 3 , dando a ver quais eram as finalidades do que estava sendo feito. Esse tipo de uso pode contribuir para mostrar uma relação de pragmatismo em relação à política externa, construindo uma imagem de proatividade. Além disso,

17. Colocou-se na tradução o sujeito indeterminado para se aproximar da gramática do inglês que não apresenta forma verbal finita, uma forma que confirma a indefinição semântica.

18. POTUS é o nome do twitter oficial do presidente Trump.

19. Vale a ressalva que o tweet em inglês apresenta todas as marcas no tempo verbal finito, o que não ocorrer com a tradução para o português. Pela razão da versão de uma língua para outra, o que não pertenceria ao inglês está entre parêneses no português, para não alterar o critério analítico. Tal critério formal se repete durante todo o artigo, quando necessário. 
cabe mencionar, dialogando com o aspecto representacional ${ }^{20}$, que, em nome da democracia e da liberdade, a ideia repressão ao regime de Maduro ganha grande destaque.

O segundo tweet ${ }^{21}$ :

Vice President Mike Pence @VP.26 de jun

The United States and Brazil are bound together by our past and our principles.

The United States was the first nation in the world to recognize Brazil's independence, nearly 200 years ago. Today, we are the two largest economies and the two largest democracies in the Americas.

No primeíro período "Os Estados Unidos e o Brasil estão unidos pelo nosso passado e pelos nossos princípios", reforça-se a ideia de que Estados Unidos e Brasil estão unidos pelo passado e pelos princípios. Sobre o Modo1, temos a presença de uma declaração de polaridade positiva, em relação ao Modo2, temos o sujeito " Os Estados Unidos e o Brasil", e a partícula verbal finita "estão"; sobre o Modo3, há o predicador "unidos" os adjuntos circunstanciais "juntos" e "pelo nosso passado e pelos nossos princípios".

No segundo período "Os Estados Unidos foi a primeira nação do mundo a reconhecer a independência do Brasil, há quase 200 anos", Pence nos fala sobre a história das relações entre EUA e Brasil, declarando a primazia dos EUA no reconhecimento da independência do Brasil. Sobre o Modo1, temos a presença de uma declaração de polaridade positiva; no que se liga ao Modo2, temos o sujeito " Os Estados Unidos" e partícula verbal de finito " foi"; em relação ao Modos, temos o complemento "a primeira nação a reconhecer a independência do Brasil" e os adjuntos circunstanciais "do mundo" e " há quase 200 anos".

No terceiro período "Hoje, nós somos as duas maiores economias e as duas maiores democracias nas Américas", o político nos fala que Estados Unidos e Brasil são as maiores economiais e democracias na América. Sobre o Modo1, temos a presença de uma declaração de polaridade positiva; no se refere ao Modo2, temos o sujeito "nós" e a partícula verbal de finito "somos"; em relação ao Modo3, o complemento "as duas maiores economias e as duas maiores democracias" e os adjuntos circunstancial "das Américas" e o adjunto modal temporal "hoje".

20. Função da linguagem ligada à maneira como representamos as experiências.

21. Tradução nossa, livre: "Os Estados Unidos e o Brasil estão unidos pelo nosso passado e pelos nossos princípios. Os Estados Unidos foi a primeira nação do mundo a reconhecer a independência do Brasil, há quase 200 anos. Hoje nós somos as duas maiores economias e as duas maiores democracias nas Américas" 
Sobre esse tweet, no que se liga ao Modo1, chama a atenção novamente a presença do modo declarativo com a presença de polaridade positiva. Esse tipo de uso, marcado pela assertividade, pode acabar, como já foi dito, contribuindo para a construção de uma relação de confiança e de segurança no que tange à percepção dos leitores.

No que se liga ao Modo2, fazem-se objetos de interesse a presença dos sujeitos "Estados Unidos e Brasil", "Os Estados Unidos" e "nós". O uso dessas formas de sujeito ratificam a dimensão protagonista dos atores citados; não obstante, o uso do pronome "nós" cria uma relação de integração entre Pence, entendido como represetante dos Estados Unidos, e o Brasil. Sobre a presença dos operadores de finito; temos a presença de dois operadores temporais no presente - períodos 1 e 3 - e um operador temporal no passado; sobre a dimensão modal destes, todos têm um caráter de constatação e de certeza. $\mathrm{O}$ uso desse tipo de operador de finito reforça o caráter de confiança em relação ao que se diz.

No se refere ao Modo3, cabe ressaltar a presença dos complementos "unidos"22, "a primeira nação a reconhecer a independência do Brasil" e "duas maiores democracias das Américas". No primeiro, há o estabelecimento de uma união entre os dois países, no segundo, uma singularização dos EUA; no último, o retorno a dimensão da união e semelhança. Ainda em relação ao Modo3, no período 1 , a presença dos adjuntos circunstanciais "juntos" e " pelo nosso passado e nossos princípios", reforça a dimensão experiencial do dizer, mostrando para o eleitor qual o motivo que une os dois países. No período 2, os adjuntos circunstancial "

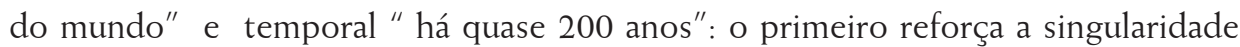
americana; e o segundo, dado ao caráter remoto da vinculação temporal, constrói o aspecto tradicional da relação entre os dois países. Por fim, no período 3, o adjunto circunstancial "nas Americas" reforça o aspecto experencial do dizer e serve para reforçar o laço entre os dois atores.

O último tweet ${ }^{23}$ :

22. Apesar de "unidos" ser um predicativo do verbo de ligação, classificação na sintaxe do português, todos os três exemplos não deixam de fazer parte do predicado da oração.

23. Tradução nossa, livre: "Os Estados Unidos e o Brasil estão unidos pelo nosso passado e pelos nossos princípios. Os Estados Unidos foi a primeira nação do mundo a reconhecer a independência do Brasil, há quase 200 anos. Hoje nós somos as duas maiores economias e as duas maiores democracias nas Américas" 
Vice President Mike Pence @VP - 27 de jun

Karen \& I met with families who fled Venezuela not to seek a better life; they came to Brazil to live, to survive. We are with you. We are fighting for youbecause we believe with all our hearts that our brothers and sisters in Venezuela deserve to live in libertad.

No primeiro período "Karen e eu nos reunimos com famílais que fugiram da Venezuela para busca uma vida melhor", Pence nos diz que a esposa e ele encontraram-se com famílias venezuelas. Em termos analíticos, nesse segmento, temos uma oração complexa, que pode ser segmentada em três partes "Karen e eu nos reunimos com famílias", "que fugiram da Venezuela", "para buscar uma vida melhor". Sobre a primeira parte, em relação ao Modo1, há uma sentença declarativa de polaridade positiva; no que se liga ao Modo2, temos o sujeito "Karen e eu" e a ausência de operador de finito; no que se liga ao Modos, temos a presença do predicador "(nos) encontramos" e o complemento "com famílias". Sobre a segunda parte, em relação ao Modo1, há presença de uma setença declarativa de polaridade negativa; em relação ao Modo2, há presença do sujeito "que"(famílias) e elipse do operador de finito; no que se liga ao Modos, há a presença do predicador "fugiram" e do complemento "Venezuela". Por fim, na terceira parte, há a presença do adjunto circunstancial "em busca de uma vida melhor", de polaridade negativa.

No segundo período, "Eles vieram ao Brasil para viver, para sobreviver", nos diz que as famílias venezuelanas emigraram para o Brasil para não morrerem . No que se liga ao Modo1, temos uma oração declarativa de polaridade positiva; sobre o Modo2, há a presença do sujeito "eles" e elipse do operador de finito; em relação ao Modo3, temos o predicador "vieram" e complemento "para o Brasil" e os adjuntos circunstanciais "para viver" e "para sobreviver". No terceiro período "Nós estamos com você", ele diz que estão com as famílias venezuelanas. Sobre o Modo1, temos uma oração declarativa de polaridade positiva; no que se liga ao Modo2, temos o sujeito "nós" e a operador verbal de finito "estamos"; sobre o Modos, há o complemento "com você".

Em seguida, temos a oração "Nós estamos lutando por você". Através dela, Pence se coloca a favor das famílias venezuelanas. Sobre o Modo1, temos uma oração declarativa de polaridade positiva; em relação ao Modo2, o sujeito "nós" e operador verbal de finito "estamos"; em relação ao Modo3, há o predicador "lutando" e complemento "por você".

Após, o vice-presidente nos diz "porque nós acreditamos de todo nosso coração que nossos irmãos e irmãs na Venezuela merecem viver em liberdade". Isto é, fala-nos que a luta pelas famílias venezuelas ocorre porque ele, Pence, e 
os representantes brasileiros acreditam que os venezuelanos desejam viver em liberdade. Nesse segemento, temos uma oração complexa. Em relação ao Modo1, temos uma oração declarativa de palaridade positiva; sobre o Modo2, temos o sujeito " nós" e a elipse do operador de finito; no que se liga ao Modo3, temos o predicador "acreditamos", o adjunto modal "de todo nosso coração" e o adjunto textual "porque". Como complemento, temos "nossos irmãos e irmãs na Venezuela merecem viver em liberdade", um segmento textual que além de complemento é também oração. Sobre ela, correlacionado ao Modo1, temos uma oração declativa de polaridade positiva, ligado ao Modo2, temos o sujeito "nossos irmãos e irmãs na Venezuela" e a elipse da operador de finito; sobre o Modo3, temos o predicador " merecem", o complemento " (para) viver" e o adjunto circunstancial "em liberdade".

No que se liga a esse tweet, em relação ao Modo1, chama a atenção a recorrência do modo declarativo com a presença de polaridade positiva ou negativa. No texto, não há presença de gradações entre os dois polos. Esse tipo de uso, marcado pela assertividade, pode, como já foi dito, contribuir para a construção de uma relação de confiança e de segurança em relação aos leitores.

Sobre o Modo2, temos a presença dos sujeitos "Karen e eu" "que (famílias)" "eles", "nós", "nós" e "nosso irmãos e irmãs". Sobre esses usos, chama a atenção a relação de pessoalidade, de coletividade e de familiaridade que eles ajudam a construir. Não obstante, há a presença de operadores verbais de finito modalizadores de tempo, duas aparições de "estamos". Isso cria uma relação de atualidade para o que está sendo dito.

Sobre o Modo3, temos a presença dos predicadores "reunimos", "fugiram", "vieram", "lutando" "acreditamos" e "merecem", processos verbais materiais, com exceção do processo mental do verbo "acreditamos", o que dá caráter concreto à situação que se está descrevendo. Os complementos "com famílias", "Venezuela", "para Brasil", "por você", "nossos irmãos e irmãs na Venezuela" e "para viver" realçam a dimensão pessoal do que está sendo dito, na medida em que centralmente reforçam a dimensão pessoal do que está sendo vivido pelas famílias venezuelanas. Por fim, há os adjuntos circunstanciais "para buscar uma vida melhor" e " para viver", "para sobreviver" e "em liberdade", o adjunto modal "de todo nosso coração" e o adjunto textual " porque"; os circunstanciais contribuem para dar a finalidade às ações realizadas pelos venezuelanos; o modal, para um caráter de intensidade e de pessoalidade; e o textual, para uma relação de articulação em relação à luta desempenha em nome dos venezuelanos e o valor liberdade.

Sobre a dimensão do contexto de situação ligado à dimensão relacional, o uso de orações do tipo declarativo com polaridades não modalizadas (positivas ou 
negativas), contribui para a criação de uma ideia de segurança com o interlocutor, como se se pudesse acreditar no que está sendo dito em virtude do enunciador ter forte confiança no conteúdo do seu dizer. Não obstante, a predominância de pronomes pessoais ou de substantivos próprios como sujeitos cria certa relação de pessoalidade em relação ao que é enunciado, criando um senso de proximidade com os leitores.

Há de se mencionar também o caráter operador temporal ligado ao tempo presente materializado na maior parte dos operadores de finito e nos predicados, o que contribui para criar certa ideia de presente e de atualidade, dando um caráter dinâmico à comunicação. Importante também mencionar a grande presença de adjuntos circunstanciais de finalidade, os quais, além de salientar a dimensão experiencial do dizer reforçando o caráter de reconstrução representacional assumido pelas orações performatizadas, constroem certa ideia de pragmatismo a respeito do ator que constrói a mensagem. Ratifica-se, através da construção do contexto de situação na dimensão relacional, a construção de um perfil confiante, pragmático, pessoal e patriótico em relação à defesa dos valores norte-americanos, com uma defesa quase que intransigente de família e de liberdade.

Articulando essa dimensão relacional do contexto de situação ao contexto da cultura, ligada à diplomacia digital via twitter e à política externa dos EUA no governo Trump, é pertinente falar de uma política de defesa de interesses que se articula mais centralmente em torno de questões emocionais, com a adoção de uma postura mais passional e pessoal em relação à defesa dos valores e interesses norte-americanos em relação à, no caso, América Latina. Não bastando isso, a própria relação com os países de quem se busca apoio é construída em termos mais pessoalizados, o que, em certo sentido, reforça a dimensão de uma bilateralidade (desigual) que se tornou o fulcro da política externa estadunidense.

\section{CONSIDERAÇÕES FINAIS}

Na comunicação diplomática e mesmo na comunicação política como um todo, na era da internet e das redes sociais, os políticos invadem o twitter, e o twitter invade a esfera política, haja vista os Estados Unidos, com Donald Trump e Mike Pence. Este processo de diplomacia (digital) tem consequências em vários âmbitos, inclusive no campo da política externa (estadunidense), que, além de sofrer modificações estruturais e direcionais, passa a ser também construída pela via digital. 
Através da análise dos tweets de Mike Pence em sua visita ao Brasil, foi possível notar uma forte presença de elementos linguístico-discursivos que, no plano interpessoal, constroem uma ideia de confiança, de pragmatismo e de passionalidade em relação à defesa dos valores e dos interesses estadunidenses na América Latina. Isso é interessante porque, além de mostrar a continuidade do monroísmo, que, desde o século XIX, caracteriza a postura norte-americana em relação aos países da latino-américa e ao Brasil, dá a ver também certa mudança nos modos de fazer política (diplomática), com uma presença mais enfática de elementos linguísticopassionais na construção do discurso político, o que pode ser uma das chaves para a compreensão da ascensão de novos atores políticos como Donald Trump.

Quando a América twitta para os americanos, ela twitta também para os linguistas, e todo um sistema e um conjunto de (novas) funções linguageiras e diplomáticas cabem em 280 caracteres. E ficam questões não respondidas. A pessoalização, o emocional e o passional não demonstrariam como uma autoridade política - vice-presidente americano - de direito internacional organiza discursos 'tweettados' em prol de uma política externa que aparenta um discurso apaziguador diante de interesses diferentes? Não seriam uma forma de esconder os pressupostos hegemônicos que a atravessa? Não seriam uma forma de 'derreter' possíveis resistências contra-hegemônicas?

\section{REFERÊNCIAS}

CASTELLS, Manuel; GERHARDT, Klaus B. A sociedade em rede. Tradução Roneide Venâncio. São Paulo: Paz e terra, 2000.

BERNARDINO, Cibele G. A metafunção interpessoal: um olhar sobre o artigo acadêmico de linguística. Revista Brasileira de Linguística Aplicada, v. 15, n. 3, 2015.

EGGINS, Suzanne. An introduction systemic functional linguistics. London and New York: Continuum, 1994.

GIL, Federico G., The Kennedy-Johnson Years. In: MARTZ, John D. (ed.). United States policy in Latin America. Nebraska: University of Nebraska Press, 1989, p. 3.

GUIDA, Alessandro. Donald Trump and Latin America. Interdisciplinary political studies. 2018. Disponível em: <http://siba-ese.unisalento.it/index.php/idps. Acesso em: 12 dez. 2018. 
HALLIDAY, Mak A. K. Spoken and written language (language education). USA: Oxford University Press, 1989.

HALLIDAY, Mak A. K.; MATTHIESSEN, Christian M. I. M. An introduction to Functional Grammar. London: Edward Arnold, 2004.

LEFFLER, MELVYN P. Trump's delusional national security strategy. how the administration ignores what made America great. Foreign Affairs, 21 December, 2017. Disponível em: $<$ https://www.foreignaffairs.com/articles/2017-12-21/trumps-delusional-nationalsecurity-strategy>. Acesso em: 19 dez. 2018.

KAHL, Colin \& BRANDS, Hall. Trump's grand strategic train wreck. Foreign Policy, 31 January 2017. Disponível em: < http://foreignpolicy.com/2017/01/31/trumps-grand-strategictrain-wreck/>. Acesso em: 15 dez. 2018.

NYE, Joseph S. O paradoxo do poder americano: porque é que a única superpotência mundial não pode actuar isoladamente. Tradução Tiago Araujo. Lisboa: Gradiva, 2005.

PELLING, Jon. When doing becomes the message: the case of the Swedish digital diplomacy. In: BJOLA, Corneliu; HOLME, Marcus (Org.). Digital diplomacy: theory and practice. London /New York: Routledge, 2015. p. 164-180.

POSEN, Barry R. The rise of illiberal hegemony. Trump's surprising grand strategy, Foreign Affairs, 13 February, 2018. Disponível em: <https://www.foreignaffairs.com/ articles/2018-02-13/rise-illiberal-hegemony >. Acesso em: 15 dez. 2018.

SEXTON, Jay. The Monroe doctrine: empire and nation in nineteenth-century America. New York: Hill and Wang, 2011.

SOUTO MAIOR, Luiz A. P. Brasil-Estados Unidos: desafios de um relacionamento assimétrico. Revista Brasileira de Política Internacional, v. 44, n. 1, p. 55-68, 2001.

THOMPSON, Geoff. Introducing Functional Grammar. London: Arnold, 2002.

US WHITE HOUSE. National security strategy of the United States of America. Disponível em: < https:// www.whitehouse.gov/wp-content/uploads/2017/12/NSS-Final-12-18-2017-0905. pdf>. Acesso em: 12 dez. 2015.

Recebido: 18/02/2020

Aceito: 25/03/2020

Publicado: 20/05/2020 